\title{
ACUTE DISSEMINATED TORULOSIS ASSOCIATED WITH HODGKIN'S DISEASE
}

\author{
BY \\ M. LEVENE AND L. MICHAELS \\ From the Department of Pathology, Crumpsall Hospital, Manchester
}

(RECEIVED FOR PUBliCATION DECEMBER 12, 1954)

It is now generally agreed that organisms, such as diphtheroid bacilli, avian tubercle bacilli, and Brucella, are secondary invaders or contaminants in Hodgkin's disease. Since certain fungi may cause granulomatous lesions which somewhat resemble Hodgkin's disease, attempts have also been made to incriminate members of this group. In particular, attention has been paid to the yeastlike organism Cryptococcus neoformans. About 18 cases have been described in which a condition resembling Hodgkin's disease was associated with active torulosis, considered by some authors as the aetiological agent.

The purpose of this paper is to report a further case in which it was clear, from a study of the lesions at necropsy, that the torulosis was a terminal event in the course of advanced typical Hodgkin's disease.

\section{Case Report}

A housewife, aged 59, was admitted to hospital in June, 1953, for treatment of leg ulcers which had recurred many times during the previous eight years. The Wassermann reaction had been found to be positive and the ulcers were suspected of being gummatous. Bacteriological examination showed Staphylococcus aureus on two occasions, $B$. proteus on two occasions, and a diphtheroid once. No yeastlike organisms were ever obtained from the lesions by microscopic or cultural examination. The ulcers were treated by rest in bed, injections of penicillin, and the local application of saline packs. They healed successfully within the following three months.

At the beginning of August she developed a cough and signs of basal congestion of the lungs. At this time the liver was grossly enlarged with a nodular surface. The tip of the spleen was also palpable. Her temperature rose to $100.4^{\circ} \mathrm{F}$. on August 5 and continued to rise daily to levels of 100 to $101.6^{\circ} \mathrm{F}$. from morning temperatures of 97 to $98^{\circ} \mathrm{F}$., in spite of the administration of penicillin and sulphamezathine. On September 7 her temperature became normal following the administration of aureomycin for one week, and it remained normal until her death.
Blood culture performed on August 31 remained sterile after 11 days' incubation.

Liver function tests performed on August 28 were as follows:

Serum bilirubin, $0.95 \mathrm{mg}$. $100 \mathrm{ml}$. ; serum alkaline p.'osphatase, 16.2 units $/ 100 \mathrm{ml}$; thymol turbidity, over 10 units; thymol flocculation, +++ ; and colloidal gold, 5 units.

On September 23 she was noted to be rapidly developing an ascites. This became very severe, and on October 13 paracentesis abdominis was performed. Examination of the centrifuged deposit of the ascitic fluid showed clumps of cells with darkly stained nuclei and scanty cytoplasm, which were interpreted as malignant cells. There were also large numbers of encapsulated yeast-like organisms, which grew on blood agar. The same organism was isolated from blood culture performed on October 14. Both were shown to be Cryptococcus neoformans.

The ascitic fluid rapidly reaccumulated. The patient became very drowsy and died on October 17.

The antibiotic therapy that she received during her last four months of life is listed in the Table, as it is thought to bear some relation to the behaviour of the cryptococcal infection.

TABLE

DOSAGE OF ANTIBIOTICS AND SULPHONAMIDES ADMINISTERED DURING LAST FOUR MONTHS OF LIFE

\begin{tabular}{|c|c|c|c|}
\hline $\begin{array}{l}\text { Antibiotic or } \\
\text { Sulphonamide }\end{array}$ & Dates (inclusive) & $\begin{array}{l}\text { Daily } \\
\text { Dosage }\end{array}$ & $\begin{array}{c}\text { Total } \\
\text { Dosage }\end{array}$ \\
\hline $\begin{array}{l}\text { Penicillin } \\
\text { (Distaquaine) } \\
\text { Soluble penicillin }\end{array}$ & 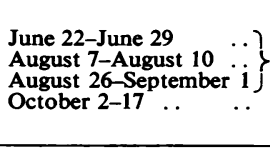 & $\begin{array}{c}0.6 \\
\text { million } \\
\text { units } \\
\text { million } \\
\text { units }\end{array}$ & $\begin{array}{c}27 \cdot 4 \\
\text { million } \\
\text { units }\end{array}$ \\
\hline Sulphamezathine & August $10-15 \ldots$ & $2 \mathrm{~g}$. & $12 \mathrm{~g}$. \\
\hline Aureomycin & September $1-8$ & $2 \mathrm{~g}$. & $18 \mathrm{~g}$. \\
\hline Streptomycin .. & October 2-17 .. & $2 \mathrm{~g}$ & $32 \mathrm{~g}$ \\
\hline
\end{tabular}

\section{Necropsy}

Necropsy was performed 58 hours after death, the body having been kept at refrigerator temperature for most of that time. 
The body was that of a thin, jaundiced woman. The peritoneal cavity contained a very large quantity of cloudy, yellow fluid.

There were enlarged lymph nodes in the paraaortic region, the hilum of the liver, the transverse mesocolon, and the pelvis. The lymph nodes were discrete, rubbery, and had a smooth surface (Fig. 1). The cut surface showed replacement of the greater part of each lymph node by homogeneous, greyish-white tissue, flecked with haemorrhagic areas.

The liver weighed $1,700 \mathrm{~g}$. and was moderately enlarged (Fig. 1). The whole of its surface was covered with yellow nodules ranging from $2 \mathrm{~mm}$. to $1 \mathrm{~cm}$. in diameter. It was hard and difficult to cut. The cut surface showed yellowish-grey nodules, $\frac{1}{2}$ to $1 \mathrm{~cm}$. in diameter, in all parts. Between the larger nodules were smaller, greenish foci, 1-2 $\mathrm{mm}$. in diameter. There was no obstruction of the extrahepatic biliary passages. The portal vein was patent.

The spleen weighed $340 \mathrm{~g}$. It had a slightly irregular surface with numerous small greyish nodules projecting from a mottled, purple background. On section most of the splenic substance was replaced by firm white tumour, intersected by red streaks (Fig. 2). There was no gross abnormality of the lungs, brain, or meninges.

\section{Histology}

The greenish foci in the liver were islands of $\frac{\bar{c}}{\frac{5}{2}}$ liver cells, often showing fatty degeneration, $\mathbb{D}$ surrounded by mature fibrous tissues containing lymphocytes, plasma cells, and bile ducts (Fig. 3). The large liver nodules were islands of characteristic Hodgkin infiltration. They were composed of enlarged reticulum cells with occasional mitoses, numerous multinucleate cells of the Dorothy Reed variety, lymphocytes, and fibroblasts. No spirochaetes were found by Levaditi's method.

The spleen and enlarged lymph nodes were $\tilde{O}$ infiltrated by Hodgkin's tissue similar to that in the liver, with, in addition, areas of necrosis.

Histological examination of each lung showed $\vec{A}$ emphysematous changes. Lying loosely within each alveolus were from one to five completely vacuolated round bodies with a brownish rim. They varied in size from 15 to $30 \mu$, and many of $\vec{\bullet}$ them were engulfed by histiocytes. Examination of of a frozen section of lung by the Sudan IV stain $\square$ showed that they were globules of fat. The Schultz reaction was negative, indicating that they

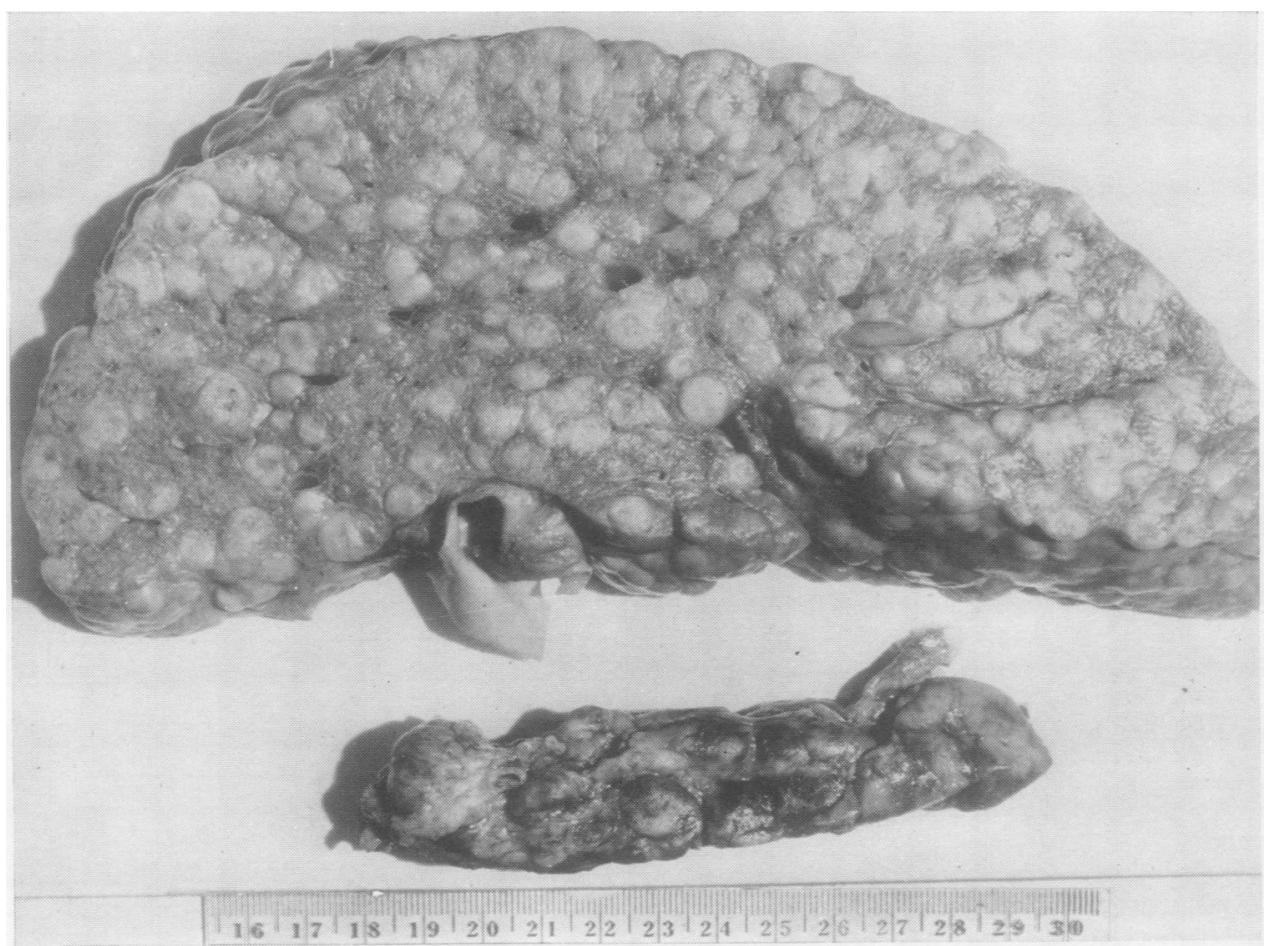

FIG. 1.-Liver and lymph nodes showing Hodgkin's disease. Note the cirrhotic changes in the liver between the tumour deposits. 


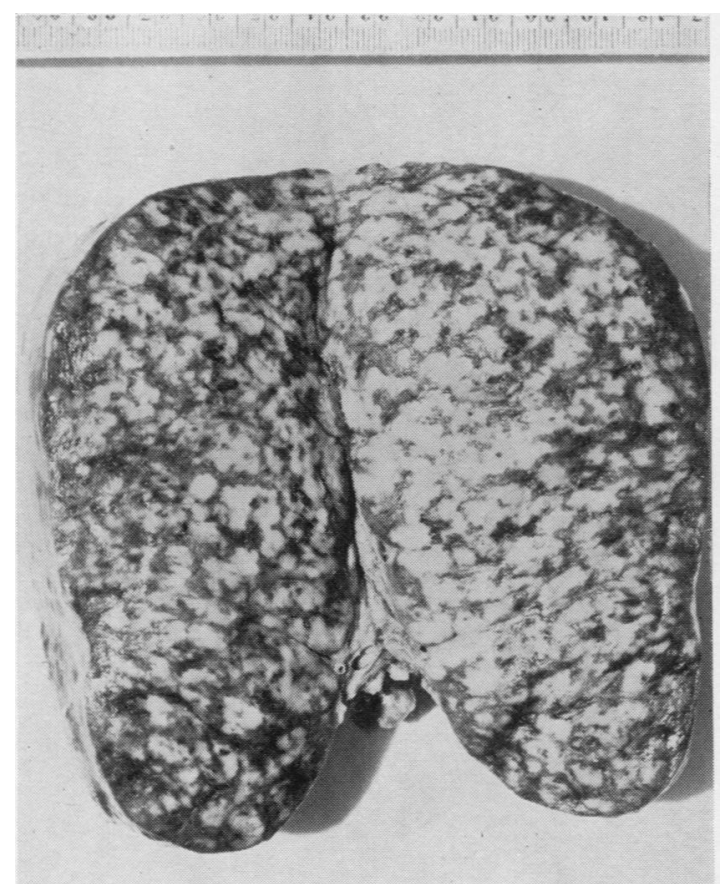

FIG. 2.-Spleen, showing almost complete replacement by Hodgkin's tissue.

did not contain cholesterol. Their presence might be interpreted as the aftermath of a pneumonia, of which there was some clinical evidence about 10 weeks before death, but the appearance of the fat as large free globules is against this and rather suggests that it was derived by aspiration. There is, however, no clinical evidence in support of this latter view.

Small collections of histiocytes were found throughout the lungs at a density of about one group to every two low-power fields. They were situated in the lumen of the alveolus close to the alveolar wall, and were often in the vicinity of a small vessel. Cryptococci were later demonstrated within these cell groups, but could not be seen in the ordinary haematoxylin-and-eosin preparations.

The cryptococci were clearly seen when smears of the deposit of ascitic fluid were stained with haematoxylin and eosin or by the P.A.S. (McManus) technique. When these stains were used on histological section of the viscera, however, the organisms could be seen only with difficulty or not at all. It was found that staining sections with haematoxylin and mucicarmine clearly demonstrated them, by staining the mucinous cell wall a deep red. Making use of this stain, most of the organs were examined for cryptococci and their lesions.

In all areas of the lungs small numbers of encapsulated cryptococci were found within the clusters of histiocytes described above. Some of the organisms occupied an intracellular position. In the adrenals occasional histiocytic collections were adjacent to the walls of the veins, and these, likewise, contained small numbers of cryptococci (Fig. 4).

Section of the brain and meninges in the region of the motor cortex showed minute lesions composed of histiocytes and cryptococci lining the subarachnoid space on both the pial and arachnoid surfaces.

The pars intermedia of the pituitary contained moderate numbers of organisms, but very little histiocytic reaction.

Groups of cryptococci were found in the following organs, associated occasionally with areas of necrosis, but with no surrounding cellular reaction: in some of the connective tissue septa of the pancreas, in occasional glomerular capillaries of both kidneys, in the thyroid, in the sinuses of

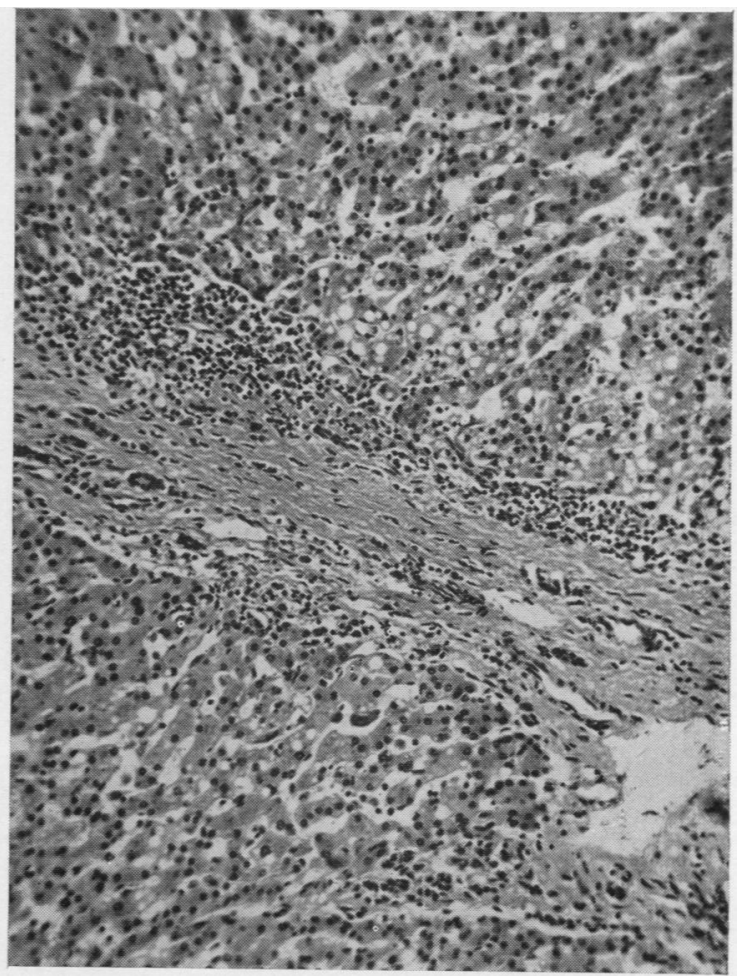

FIG. 3.- Liver, showing fatty change and a band of fibrous tissue associated with lymphocytes. (Haematoxylin and eosin. $\times 100$.) 
some abdominal lymph-nodes, and in the spleen. No cryptococci were found in single sections taken from two blocks of the liver.

\section{Mycology}

The organisms were round and varied from about 3 to $8 \mu$ in diameter. Occasional budding forms were present. In the tissues and in the ascitic fluid the cryptococci were surrounded by a wide capsule which was not stained in any of the staining procedures that were used (Fig. 5). The capsule was not present when the organism was grown in culture. The periphery of the organism stained a deep red by P.A.S. and mucicarmine, while the inner part stained pink by these stains.

The organism grew easily under aerobic conditions on most of the usual laboratory media. After 48 hours' incubation on horse blood agar at $37^{\circ} \mathrm{C}$. it appeared as brownish-yellow, raised, round colonies about $0.5 \mathrm{~mm}$. in diameter. Growth was slow at room temperature. No gas was produced when the organism was grown in glucose, saccharose, lactose, mannitol, galactose, or dulcitol.

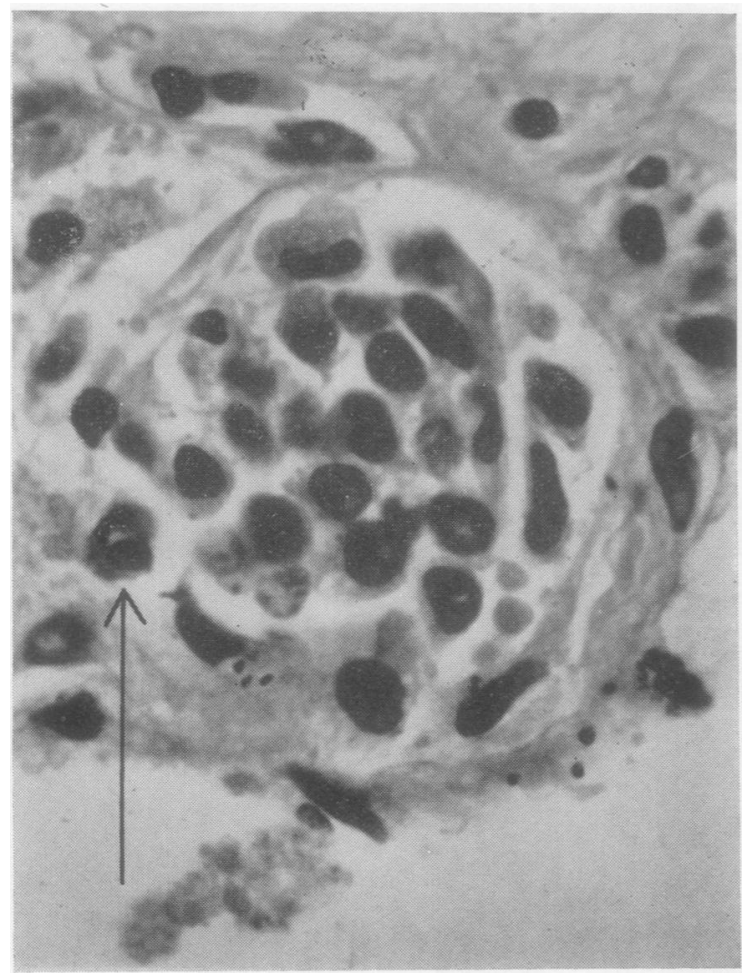

FIG. 4-Edge of vein in adrenal showing a clump of histiocytes with a single intracellular cryptococcus (marked by arrow) and staining red in section. (Haematoxylin and mucicarmine. $\times 900$.)

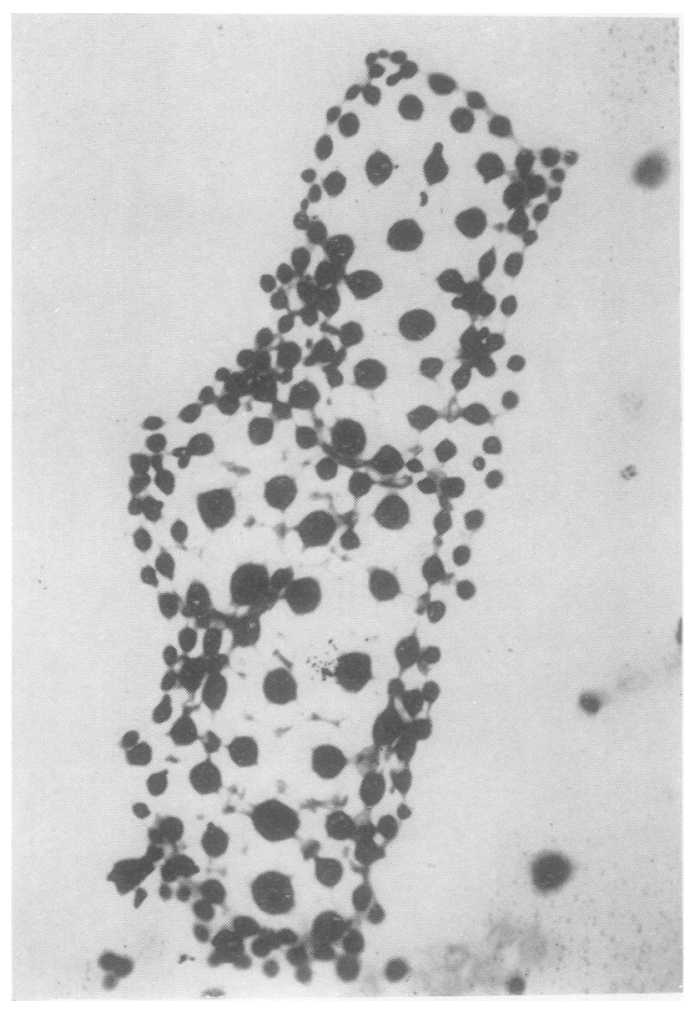

FIG. 5.-Clump of cryptococci from ascitic fluid, showing the wide unstained capsule around each organism. (P.A.S. $\times 450$ ).

No mycelium was found in the tissues or by prolonged growth of the organism in corn-meal agar at room temperature. Ascospores were not seen when the organism was grown on carrot-gypsum slopes. Intraperitoneal injection of saline suspensions of cryptococci from culture into mice resulted in death in from five to six weeks after inoculation. Large numbers of cryptococci were found in the viscera of the mice. The complete mycological identification of this organism as the pathogenic form of Cryptococcus neoformans was performed by Dr. J. Walker, of the Mycological N Reference Laboratory, London School of Hygiene $\mathrm{C}_{\mathrm{\omega}}$ and Tropical Medicine.

\section{Discussion}

It is very unusual for Hodgkin's disease to $\stackrel{\mathbb{R}}{\rightarrow}$ present clinically with liver failure as the pre- 0 dominant feature. Fairbank (1953) describes three such cases and states that there are no previous reports in the literature. In two of his cases the liver was diffusely involved by Hodgkin's deposits, but there is no mention of cirrhotic changes. In the case described here the acute liver failure was 
due to the remarkable combination of widespread Hodgkin's lesions in the liver with portal cirrhosis.

The association of cirrhosis with Hodgkin's disease of the liver must be very rare, since mention of only one comparable case was found in the world literature (Steiner, 1936).

It is possible, therefore, that the cirrhosis was pre-existing. Hodgkin's disease developing in such a liver might produce a much more widespread growth than usual.

It would seem equally possible that the cirrhotic lesions arose as a result of long-standing diffuse Hodgkin's disease involving the liver. Small focal necroses of areas of liver unaffected by the Hodgkin's lesions are said to be common in Hodgkin's disease and result, perhaps, from an interference with the lobular blood supply due to giant-cell embolism (Pullinger, 1932). It is possible that a slower vascular interference might cause, not necrosis, but fibrosis. It should be stressed, however, that apart from the cirrhotic changes in the liver the histological features of the liver, spleen, and lymph nodes were typical of Hodgkin's disease.

Infection with Cryptococcus neoformans, in the great majority of cases, mainly involves the central nervous system, either as a diffuse meningitis or as a granulomatous lesion of the brain. In this case there were no neurological symptoms or signs and, although an early cryptococcal meningitis was found histologically, it was but a small part of a disseminated infection, the brunt of which was suffered by the lungs and ascitic fluid. So great were the numbers of organisms found in the latter that it is not surprising that there was a positive blood culture, which is uncommon in cases of torulosis.

The fact that the cryptococcal disease took the unusual form of an overwhelming, acute infection may be related in this case to the heavy antibiotic therapy which the patient received in the last three months of her life. It is of interest that Symmers' second patient (1953), who received penicillin, streptomycin, aureomycin, and chloromycetin within the last six weeks of life, also had a fulminating infection. It is not yet known whether antibiotics directly stimulate the multiplication of Cryptococcus neoformans as occurs with Candida albicans (Foley and Winter, 1949).

It would appear to be established that there is some relationship between Hodgkin's disease and torulosis, since the number of described cases showing association of the two diseases is too great to be accidental. Gendel, Ende, and Norman (1950) found 13 cases in the literature and described one of their own, a total of $8.5 \%$ of all the then reported cases of torulosis. Since then four further cases have been described (Rodger, Terry, and Binford, 1951 ; Collins, Gellhorn, and Trimble, 1951 ; Holmes and Hawks, 1953 ; Symmers, 1953). Moreover, Gordon (1932) isolated a form of this organism from the lymph nodes of two cases of Hodgkin's disease, while Collins et al. (1951) obtained it by gastric aspiration in a case of Hodgkin's disease showing no clinical evidence of cryptococcal infection.

The nature of the association is still in doubt. In our case there is strong evidence that the cryptococci arose as a terminal infection in a case of typical Hodgkin's disease. The acute character of the infection is in sharp contrast with the advanced state of development of the Hodgkin's lesions. Moreover, most sections of the neoplastic areas showed no cryptococci when stained with mucicarmine. Where cryptococci were seen in proximity to the lesions it was clear that their presence was incidental, as in the abdominal lymph nodes in which yeasts were found in the peripheral sinuses but not in the adjacent neoplastic tissue.

Some authors consider, however, that the Hodgkin's lesions in their cases were the result of infection with cryptococci. Symmers (1953), for instance, regards the Hodgkin's lesions in his first case as an atypical granulomatous reaction to the fungus infection. Yet his case, with some of the other cases where a similar claim is made, may be equally interpreted as Hodgkin's disease complicated by cryptococcal infection. The presence of cryptococci in the original biopsy material taken three years before death is not conclusive proof, in Symmers' case, that cryptococci initiated the Hodgkin's lesions. The latter were typical of lymphadenoma in their histological features, their distribution, and, in the case of the superficial lymph nodes, in their reaction to irradiation. It is difficult to accept that an organism can produce granulomatous lesions only in the brain and skin while stimulating the development of reticulosarcoma-like changes elsewhere in the body. It is possible that the presence of the fungi in the neoplastic lesions was accidental. At necropsy of Symmers' case they were scanty in the Hodgkin's tissue and absent from the reticulosarcoma, but they were easily found in the granulomatous lesions of the brain and skin. In our case the presence of cryptococci in any organ of the body can be accounted for by the septicaemia, and this may have been present at some stage of the disease in Symmers' case.

The explanation for the association between the two diseases may be that cases of Hodgkin's disease 
are peculiarly susceptible to torular infection, owing to a derangement of immunity mechanisms. It has been shown that an anergic state to intracutaneous tuberculin develops in the course of Hodgkin's disease in the majority of cases (Reed, 1902 ; Hoffmann and Rottino, 1950). Dubin (1947) also found that the incidence of positive serological reactions for syphilis was lower in Negro cases with Hodgkin's disease than in the Negro population in general. It may be that in Hodgkin's disease there occurs, likewise, a deficiency of antibody normally providing defence against cryptococci.

It is probable that some cases of torulosis escape diagnosis both during life and at necropsy. Attention was drawn to the presence of a cryptococcal infection in this case only just before death when the organisms were isolated from the ascitic fluid and the blood. The patient at this time showed no pyrexia or any other features that indicated that she was suffering an overwhelming infection. At necropsy there was no gross evidence of infection and no fungi were seen on microscopical examination of tissue sections stained by the usual methods. Only when, on the advice of a mycologist, sections were stained with haematoxylin and mucicarmine was it possible to identify cryptococci in the tissues. We would, therefore, recommend the routine use of this stain in the histological examination of pathological material for yeasts. The diagnosis of torulosis should be especially considered in the investigation of cases of Hodgkin's disease.

\section{Summary}

A case of Hodgkin's disease complicated by torulosis is described.
The clinical features were those of acute hepatic failure. At necropsy it was found that multiple Hodgkin's lesions in the liver were associated with portal cirrhosis.

Cryptococcus neoformans was isolated from the blood and ascitic fluid shortly before death. The torular lesions found at necropsy were microscopic, disseminated collections of histiocytes and cryptococci.

The relationship between Hodgkin's disease and torulosis is discussed. The possibility of heavy antibiotic therapy stimulating the cryptococcal infection is mentioned.

We wish to thank Dr. J. Davson, Group Pathologist, North Manchester Group of Hospitals, for his help and advice, and Dr. R. W. Luxton, for permission to publish this case, which was under his care at Crumpsall Hospital. We are grateful to Dr. J. Walker, of the Mycological Reference Laboratory, for full identification of the yeast. and to Miss $J$. Perry for the photographs.

\section{REFERENCES}

Collins, V. P., Gellhorn, A., and Trimble, J. R. (1951). Cancer, 4, 883 Dubin, I. N. (1947). Ann. intern. Med., 27, 898.

Fairbank, W. H. D. (1953). Canad. med. Ass. J., 69, 315.

Foley, G. E., and Winter, W. D. (1949). J. infect. Dis., 85, 268.

Gendel, B. R., Ende, M., and Norman, S. L. (1950). Amer. J. Med., 9,343 .

Gordon, M. H. (1932). In Rose Research on Lymphadenoma. Wright, Bristol.

Hoffmann, G. T., and Rottino, A. (1950). Arch. intern. Med., 86, 872. Holmes, S. J., and Hawks, G. H. (1953). Canad. med. Ass., J., 68, 143. Pullinger, B. D. (1932). In Rose Research on Lymphade noma.

Reed, D. M. (1902). Johns Hopk. Hosp. Rep., 10, 133.

Rodger, R. C., Terry, L. L., and Binford, C. H. (1951). Amer. J. clin. Path., 21, is3.

Steiner, P. E. (1936). Arch. Path., Chicago, 22, 130.

Symmers, W. St. C. (1953). Lancet, 2, 1068. 